Tarih Kültür ve Sanat Araştırmaları Dergisi

Revue des Recherches en Histoire Culture et Art مجلة البحوث التاريخية والثقافية و الفنية
Vol. 7, No. 4, November 2018

Copyright (C) Karabuk University http://kutaksam.karabuk.edu.tr

\title{
DOI: 10.7596/taksad.v7i4.1835
}

Citation: Saubanov, K., \& Nikolaev, M. (2018). Evolution of the Content of the Market Category at Different Stages of its Development. Journal of History Culture and Art Research, 7(4), 192-198. doi:http://dx.doi.org/10.7596/taksad.v7i4.1835

\section{Evolution of the Content of the Market Category at Different Stages of its Development}

\author{
Kabir Saubanov ${ }^{1}$, Mikhail Nikolaev²
}

\begin{abstract}
The "market" concept is one of the key concepts of modern economic theory, as well as economic practice. It plays an exceptional role in understanding and explaining the properties and patterns of behavior of not only individual economic agents, but also economic systems in general. At the same time, up to the present time there is no unified, unconditionally accepted by all researchers definition of the market category, there are about two hundred of which. Such a multitude of definitions, most of which have a narrowly specific, partial character and are applicable only for individual cases, attests in the first place to the extremely high complexity and ambiguity of the content of the market category, as well as its large information capacity. All this certainly speaks about the relevance of the chosen research topic. The essence and content of the market concept at various stages of economic evolution are analyzed in the paper; author's interpretation of the essence of the market and the main components of its content is offered. Among these components, the most important are the freedom of entrepreneurship, competition and market infrastructure, the individual elements of which are usually identified with the market. The authors analyze the subordination of market elements and their interaction and show that many other market elements (the next order) can be logically derived from the main constituents of the content, resulting from both their interaction with each other and the response to their interaction with the continuously developing external environment.
\end{abstract}

Keywords: Market, Essence and content, Freedom of entrepreneurship, Competition, Market infrastructure.

\footnotetext{
${ }^{1} \mathrm{PhD}$ in Economics, associate professor, Institute of Management, Economics and Finance, Kazan Federal University. E-mail: Ksaubanov@mail.ru

${ }^{2}$ Doctor of Economics, professor, Russian University of Cooperation, Kazan Cooperation Institute (Branch). Email:mnikolae@yandex.ru
} 


\section{INTRODUCTION}

The market concept comes from ancient times, when it was viewed as an area in the center of the city, where the products of individual labor were offered for exchange or sale. If a transaction was carried out, this meant that individual labor became public, i.e. its need for other people was confirmed.

However, with the development of transport and communication systems, it became possible to exchange or sell without a rigid binding to a location, and the definition of the market began to change and become more complex. It begins to be identified first with trade, and then with the totality of all relations in the sphere of exchange as a whole. At the same time, the former values of the market continued to be kept and used both as a square, as trade, and many others.

The first attempt to give the market a scientific definition belongs to the French scientist A.A. Cournot (1924), who believed that economists under this term mean not just the area where transactions are carried out for the sale of certain items, but an area where the free relationships between buyers and sellers quickly and easily lead to the equalization of prices for the same goods.

Ideas of A.A. Cournot was supported and developed by W. Jevons (1911), an English economist who believed that the market could be any number of people entering into business relations and signing deals for the purchase and sale of any goods. He suggested that in any large city there can be as many markets as there are industries that are important for the city. However, these markets do not need to be tied to this particular place. And merchants can nevertheless form a market, regardless of their location in the city or even the district provided that they maintain close business ties through meetings and fairs, through the publication of price lists or in other ways.

Ideas of A.A. Cournot and W. Jevons were generalized by the English economist, the founder of the "Cambridge school" A. Marshall (2013) and laid the foundation of his market concept, which prevails in science to this day. According to this concept, a market is not a square in the center of a city, and not the place of sales. It is such a space where the interaction between buyers and sellers or supply and demand for good causes the formation of a single price, which is given a key role here. It sets the essence and boundaries of the market, which either decreases to the size of the area or, on the contrary, grows to the size of a city, region, world, depending on the boundaries of the interaction of supply and demand and the formation of a single price. Beyond these borders there are different prices and, accordingly, a different market.

The concept of A. Marshall, being one of the most interesting and fruitful, at the same time is not without certain drawbacks. The main one is seen in the fact that it is based not on the internal, but mainly on the external side of market relations - pricing. While under certain conditions, a market can exist and function even without prices at all. It is about barter markets that were not only up to the origin of money, but had and are taking place in any economy of varying degrees of development, for example, with high inflation, financial crises, unstable prices, etc. So, F. Kotler (1984) stressed that in the modern US, thousands of people are returning to barter, exchanging their services and goods for them at all without the help of money. Some dodgers, says F. Kotler, manage to even get a haircut, use dry cleaners or treat teeth without paying with money. It follows that price is although the most important attribute of the market, but not the only one, and new additional studies are required on the problem of the essence and content of the market and their evolution.

\section{METHODS}

Various methods were used in the work: 
1) A historical method that involves studying not only the present, but also the past in the development of the phenomenon under investigation. This allowed us to identify and characterize the main stages in the market formation and clarify the features of the evolution of the analyzed category. Methodologically, this method relies primarily on the studies of M. Weber (2005), W. Sombart (1913) and A. Toynbee (1934);

2) The abstract-logical method, which is an instrument of scientific abstraction, and allowed to formulate the definition of the market as a form of communication and resolution of the contradiction between production and consumption, and also to structure the content of the market;

3) The comparative analysis method which made it possible to differentiate the characteristics of the essence and content of the market category in relation to the different periods of its formation and development and to compare them with each other.

\section{RESULTS AND DISCUSSION}

Let us consider the essence and content of the category "market" from a slightly different point of view compared to how it was done in the other examples above.

In any economic system, we can always observe a huge amount of time and again, essentially endlessly, repeating processes of purchase and sale, credit and banking and stock exchange transactions, various intermediary operations, etc., which ultimately form a continuous and complex process of commodity circulation. In all these operations, a seller, a buyer, an exchange intermediary, and other economic agents realize only their own economic interests, and pursue any of their strictly individual goals. But all this observed set of processes is not a market as such, but only its external manifestation.

However, no matter how much these processes are outwardly different, at the same time, in their essence, and in their deep ties they all ultimately express the same essence: the connection between production and consumption as the two extreme phases of the reproductive process into one indivisible whole. One can even say that it is this very link which closes the complex chain of continuous sequential movement of the product, and makes the process of reproduction by oneself, such as we are accustomed to count and see.

A. Smith (2013) has expressed the idea that the market is a natural process generated by the actions of separate individuals who pursue only personal goals, but an economic order is formed from the chaos of these actions.

We also note that the relationship between production and consumption is far from unambiguous and contradictory. On the one hand, it is well known that production exists only for consumption, and production for the sake of production itself is meaningless. However, it is difficult to subordinate production to consumption, and sometimes it is impossible. This contradiction between production and consumption is regularly manifested either in the deficit of certain goods or in their overproduction, what disrupts the normal course of the reproductive process and is the main factor in economic crises.

In principle, this contradiction can be eliminated in various ways. First, by direct calculation of what is required for the consumption sphere and the corresponding organization of production, i.e. actually through the process of developing a plan. Secondly, the organization of an equivalent exchange system without any special calculation of the goods produced and consumed, i.e. through a free market mechanism. Schematically this can be shown in the following figure: 


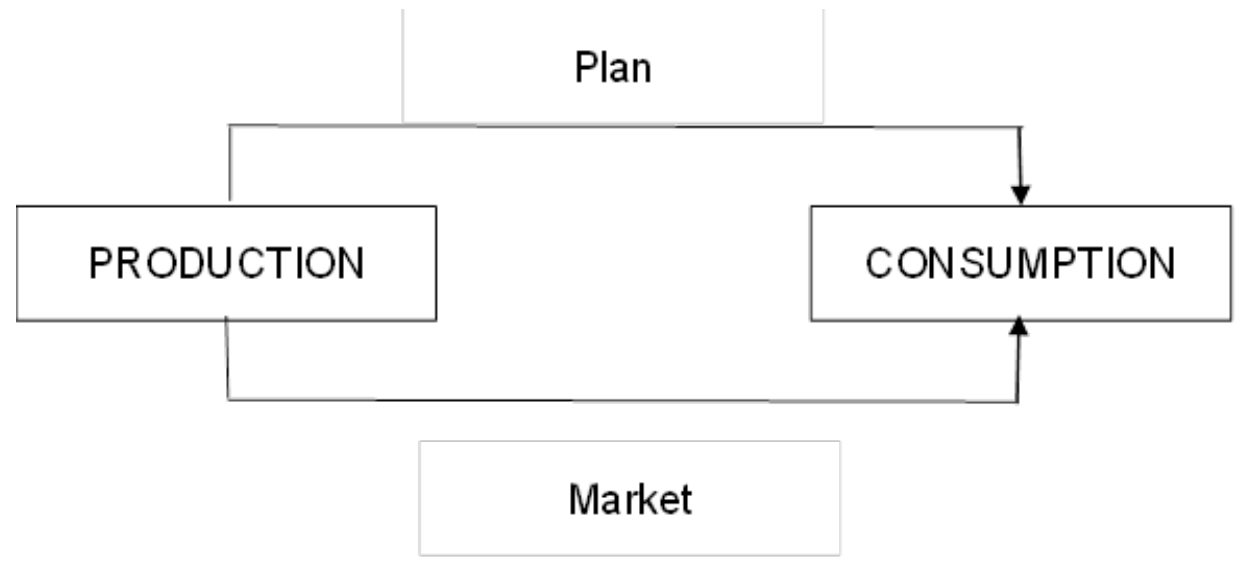

Fig.1. Scheme of connection between production and consumption

From the figure, we see that the production (which is the initial phase of the reproduction process and in principle always subordinated to consumption) and consumption which is the final phase of the named process, can be linked together and consistently either through the mechanism of the plan, or the market, or through both mechanisms simultaneously.

Returning to the essence of the market, we emphasize that it manifests itself in its very nature, acting as a specific form of communication and resolving (removing) the contradiction between production and consumption. This connection is hidden from its direct perception and expresses the stable internal unity of market relations. As for its external appearance, it occurs through numerous and diverse components of the market's content, for example, through constantly improving types and forms of sales, updated credit and financial mechanisms, new advertising, developing management, etc., allowing to remove another arisen or warn emerging contradiction between production and consumption at a new stage of economic development.

Let us consider in more detail the content of the category "market" through the prism of its main elements (we call them elements of the first order). The first and at the same time the most important of them is the freedom of entrepreneurship. It means that any private enterprise or firm can strictly carry out one or another production program strictly according to its own interests, including its changing, its closing or, alternatively, its expansion. And only under such conditions manufacturers can adequately react to all requests of customers, while adapting to the real-forming monetary demand. Of course, this freedom, as in most other cases, is not absolute, but only relative. That is, manufacturers are obliged to produce not everything at all, what they want, but what buyers need and what they are ready to pay for.

The next (second) element of content in the foregoing understanding of the market is competition, the role of which is exceptionally high and difficult to overestimate. It generally means such a dispersal of economic power in the society between individual actors, when no one is able to seriously affect the current situation, to discourage at its discretion the expansion or reduction of individual industries, what undoubtedly contributes to the increase in the flexibility and efficiency of production, forcing economic agents not simply to produce, but to produce exclusively for consumption, thereby removing the contradiction between production and consumption and ensuring the continuity of the production process (Nedenin, 2015; Kelarev, 2003).

The two named main elements of market content: the freedom of entrepreneurship and competition are very closely interrelated, essentially intertwined and inseparable from each other. The first of these elements makes the connection between production and consumption through an exchange possible in principle, and the second creates real prerequisites for ensuring high efficiency and quality of this 
connection. In the absence of competition, monopoly develops, the relationship between production and consumption becomes more complex and confusing, and at the micro level the manufacturer's interests undoubtedly predominate and the buyer's requests are fully or partially ignored.

It is most appropriate to consider the market infrastructure as the next third element of content. This is a special collective element with its own complex internal structure. It includes a large system of strictly specialized organizations, including exchanges, banks, insurance companies, auctions, fairs, shops, etc., which, firstly, ensure the interconnection and unity of all other elements, and, secondly, to some extent make their very existence possible. So, it is impossible to ensure full freedom of entrepreneurship in the absence of commercial and other types of insurance, as well as without the network of commercial banks. Equilibrium prices are not possible in the absence of exchanges, and it is impossible to achieve effective interaction of numerous market agents without shops, fairs and auctions. However, the most important feature of market infrastructure is that it is the most visible and directly observable part of the category "market" content. Therefore, the market as a whole itself is often identified with the market infrastructure, as well as with its separate components, for example, with shops, squares in the centers of cities or districts, trade outlets, etc.

Thus, we see that all three of the above elements of market content understood as a form of communication and resolving the contradiction between production and consumption through exchange, are subordinated in a certain way. Without the first, the freedom of enterprise, the unity of production and consumption and the resolution of the contradiction between them through exchange cannot be ensured; without the second, competition, real freedom of entrepreneurship and high production efficiency are unattainable; without the third element, market infrastructure, neither freedom of enterprise nor competition is possible. And in this way the connection between the elements and content is closed in a kind of ring.

Subordination also manifests itself in the fact that it is possible to derive numerous derivatives (secondary) elements from the interaction of the main elements of market content, such as: development of personal interests for agents of the market; striving for technological progress; the tendency to the formation of equilibrium prices, etc.

So, for example, personal interest in the market prevails over all others, which directly follows from the freedom of entrepreneurship and competition. Realization of personal interest is a condition of survival in the system of market relations. But on the other hand, both an entrepreneur (manufacturer) and a buyer, pursuing only their own, opposing to each other interests, eventually come to a price that suits both, i.e. to the equilibrium price.

It is easy to see that the desire, for example, to achieve technological progress is also conditioned by the freedom of entrepreneurship and competition. If an enterprise overtakes, its competitor is looking for opportunities for technical improvement of its production, and so on ad infinitum. Thus, the desire for technical progress becomes an internal motive for the market organization of production, an element of its content.

In this subordination, there is a certain pattern testifying to that the above main elements of market content not only express a single essence, but also act as parties to the same link. They form some kind of skeleton, on which, interacting simultaneously with each other and with the environment, they form new derivative elements, thus deepening and unfolding the content of the market in accordance with the requirements of the era. 


\section{SUMMARY}

The conducted research allows some conclusions to draw.

1. Exceptional variety of definitions of the category "market" is unavoidable and justified. It is associated with two reasons: 1) the complexity and high information capacity of the content of the category "market" which cannot be expressed by a single definition. Each researcher, depending on the task at hand, finds his/her own aspect in this content; 2) and the historical character of the definition of the market. In ancient times, the market was rightly called the square in the center of a city. The subsequent epochs left their imprint and made their amendments to this approach.

2. The most common definition of the market is its understanding as a form (or mechanism) of communication and resolving the contradiction between production and consumption through exchange. Historically, it originated precisely as this form and acts with the inevitability of the law as a natural and independent force in the conditions of the division of labor and the absence of direct information about the needs. From this definition, one can derive most of the other definitions as special cases.

3. The content of the market, which, unlike the essence (the resolution of the contradiction between production and consumption through exchange), includes not only internal links, but also interaction with the external environment; it continuously develops and changes, constantly adapting to an evolving environment. Only the essence remains unchanged.

4. The content of the market has a complex multi-element composition and is subordinated. The role of the main elements (first-order elements) is fulfilled by the freedom of entrepreneurship; competition; market infrastructure. The content develops in the process of their interaction with each other and with the environment.

\section{CONCLUSIONS}

In conclusion, let us pay attention to the exceptional importance of the interaction of market and planned mechanisms in ensuring the unity of production and consumption as the initial and final phases of the reproductive process. For a long time, plan and market opposed to each other, being the main objects of ideological differences between East and West, although in reality from the economic point of view they have always been and remain only in different ways to remove the contradiction between production and consumption and ensure their unity. They have always been and remain complementary to each other and it is this property that serves today as the basis for the formation of effective models of mixed economic systems.

\section{ACKNOWLEDGEMENTS}

The work is carried out according to the Russian Government Program of Competitive Growth of Kazan Federal University.

\section{REFERENCES}

Cournot, A. A. (1924). Mathematical principles of the theory of wealth, Chapter IV. Jena.

Jevons, W. S. (1911). Theory of Political Economy, Chapter IV. London: MACMILLAN.

Kelarev, V. V. (2003). Competition: a methodological view of the essence of the category. University Proceedings of higher education institutions from North-Caucasus region, 2, 73-76. 
Kotler, P. (1984). Marketing essentials, The Prentice-Hall series in marketing. Prentice-Hall.

Marshall, A. (2013). Principles of economics, (8th ed.). Palgrave Macmillan.

Nedein, N. V. (2015). Theoretical studies of the formation and development of competitiveness of organizations. Bulletin of the Samara State University, 2(124), 157-163.

Smith, A. (2013). An Inquiry into the nature and causes of the wealth of nations, produced by Colin Muir, and David Widger. Gutenberg.

Sombart, W. (1913). Bourgeois: studies on the history of the spiritual development of modern economic man. Lpz.

Toynbee, A. J. (1934). Comprehension of history. Oxford university press.

Weber, M. (2005). The protestant ethic and the spirit of capitalism. Taylor \& Fransice. 